\title{
Why did researchers not use realistic doses in animal studies of bisphenol A?
}

\author{
Wolfgang Völkel ${ }^{1,2}$
}

Received: 22 August 2016 / Accepted: 25 August 2016 / Published online: 8 September 2016

(C) Springer-Verlag Berlin Heidelberg 2016

Bisphenol A (BPA) is a high volume production chemical. BPA has been identified as an endocrine disruptor, and more than 5000 of safety-related studies have been published. Regulatory agencies around the world evaluated this body of BPA toxicology data, and so the FDA previously decided that BPA is safe at current exposure levels http:// www.fda.gov/Food/IngredientsPackagingLabeling/FoodAdditivesIngredients/ucm355155.htm.

Current exposure levels mean an average dose of $<0.1 \mu \mathrm{g} / \mathrm{kg}$ b.w. a day.

However, a group of researchers still believe that doses between $25 \mu \mathrm{g} / \mathrm{kg}$ b.w. and $50 \mathrm{mg} / \mathrm{kg}$ b.w. are still relevant (Hass et al. 2016; Mandrup et al. 2016), and these studies were promoted in an editorial of Andrology by Vandenberg and Prins with "Clarity in the face of confusion: new studies tip the scales on bisphenol A (BPA)" (Vandenberg and Prins 2016).

They argue that new studies ("In this issue of Andrology, two new studies meet exactly this demand") will help to assess better the adverse effects of BPA. But a first look at the applied doses shows that the lowest dose used was $25 \mu \mathrm{g} / \mathrm{kg}$ b.w. and is thereby nearly 500 -fold and the highest is $1,000,000$-fold above the current daily exposure of humans. The dose of $25 \mu \mathrm{g} / \mathrm{kg}$ b.w. corresponds to a daily uptake in adults $(60 \mathrm{~kg})$ of $1500 \mu \mathrm{g}$ of BPA a day and leads to a urinary excretion of a similar amount of BPA.

Wolfgang Völkel

Wolfgang.Voelkel@1gl.bayern.de

1 Department of Chemical Safety and Toxicology, Bavarian Health and Food Safety Authority, 80538 Munich, Germany

2 Department of Toxicology, University of Würzburg, Würzburg, Germany
While one of the authors of the editorial wrote in 2010 in Environmental Health Perspectives "biomonitoring studies should be used by regulatory agencies to assess human exposure levels" and further on "Center of Disease Control $(C D C)$ analytical procedure ... is the gold standard" (Vandenberg et al. 2010b), Vandenberg and Prins praise the studies of Hass et al. and Mandrup et al. in such a way that "Regulatory agencies have two new studies that meet the criteria on their 'wish lists' for inclusion in chemical risk assessments". But the CDC and others only find a median level of about $2 \mu \mathrm{g} / \mathrm{L}$ in urine, corresponding to a dose of approximately $0.05 \mu \mathrm{g} / \mathrm{kg}$ b.w. ( $>500$-fold below $25 \mu \mathrm{g} / \mathrm{kg}$ b.w.) summarized in Table 3 of a recently published study (Völkel et al. 2008). If you use external exposure assessment, the highest doses were calculated for toddlers with up to $0.85 \mu \mathrm{g} / \mathrm{kg}$ b.w. per day, which was about 30 -fold below the lowest dose administered by Hass et al. and Mandrup et al. http://www.efsa.europa.eu/sites/default/files/scientific_output/files/main_documents/3978part1.pdf.

What should regulatory toxicologists do with such studies?

Regulatory toxicologists use for an accurate risk assessment both hazard and exposure data. Hazard data may be addressed by the studies of (Hass et al. 2016; Mandrup et al. 2016) dealing with sexual maturation, weights, and histopathology of reproductive organs, which may be on the "wish list," but also these data are at least in part already available, as discussed in detail elsewhere http:// www.efsa.europa.eu/sites/default/files/scientific_output/ files/main_documents/3978part1.pdf.

In addition, adverse effects should be occurring at relevant doses! Why did Hass et al. and Mandrup et al. not apply doses as low as $0.1 \mu \mathrm{g} / \mathrm{kg}$ b.w. per day? Excellent data sets of human exposure to BPA are available, as described before. In addition, Hass et al. and Mandrup 
et al. observed effects at mammary gland or reduced sperm counts at their lowest dose, but not at higher doses showing non-monotonic dose responses (NMDR). Did the observed effects increase with lower doses below $25 \mu \mathrm{g} / \mathrm{kg}$ b.w. per day?

In the case of the term "low dose," the lowest applied dose up to 500-fold above the human exposure assessed by biomonitoring data is only difficult to understand and may not on the "wish list" of regulatory toxicologists. Therefore, you as regulatory toxicologists will agree to Teeguarden and Hanson-Drury, who reviewed the term low dose recently and wrote in the abstract "we found that the "low-dose" moniker describes exposures covering 8-12 orders of magnitude, the majority (91-99\% of exposures) being greater than the upper bound of human exposure in the general infant, child, and adult U.S. population" (Teeguarden and Hanson-Drury 2013). This is also true for many other countries, such as Germany where on average levels of $<0.09 \mu \mathrm{g} / \mathrm{kg}$ b.w. and highest at $1.2 \mu \mathrm{g} / \mathrm{kg}$ b.w. in adults and $0.6 \mu \mathrm{g} / \mathrm{kg}$ b.w. in infants were observed (KasperSonnenberg et al. 2012; Koch et al. 2012; Völkel et al. 2008, 2011). All these doses are clearly below the current temporary tolerable daily intake (t-TDI) of $4 \mu \mathrm{g} / \mathrm{kg}$ b.w.

In addition, as discussed elsewhere, the kinetics in rat and in humans are quite different in the case of BPA, since in contrast to the rat, humans almost quantitatively convert BPA to the corresponding glucuronides and sulfates. Details were discussed in Doerge et al. and the authors concluded "Furthermore, these findings highlight significant differences between the elimination of BPA in rats by biliary secretion versus non-human primates (Kurebayashi et al. 2002) and humans (Völkel et al. 2002) where elimination is dominated by renal excretion" (Doerge et al. 2010a). Therefore, toxicokinetics have to be considered for a correct dose range in rats if the data should be used for regulatory purposes. For BPA a lower dose in rats compared to humans should provide comparable internal doses of the parent compound BPA, which is responsible for the adverse effects.

Both authors of the editorial and these of the two studies use the term NMDR. This is a typical topic related to compounds showing endocrine activity. Recently an external scientific report for the European Food Safety Authority (EFSA) was published discussing especially the NMDR and addressed six so-called checkpoints (more or less statistical tools which address both random and non-random errors), which should be fulfilled to classify a compound as chemical showing NMDR https://www.efsa.europa.eu/ $\mathrm{de} /$ supporting/pub/1027e. Although "the most common chemical substances are bisphenol A (14\% of datasets)", BPA was not a compound that fulfills all six checkpoints. In contrast, a review by Vandenberg is titled "Non-monotonic dose responses in studies of endocrine disrupting chemicals: bisphenol A as a case study" used exactly BPA as model for NMDR (Vandenberg 2014) and Vandenberg concluded that "Taken together, these results provide strong evidence for NMDRCs in the EDC literature, specifically for BPA".

Why did Hass et al. and Mandrup et al. not consider the kinetics of BPA, which are known since 2002 (Völkel et al. 2002)? Do they believe in the criticism of Vandenberg et al. (Vandenberg et al. 2010a) that the data of Völkel et al. are not reliable?

It was Teeguarden, Doerge, and some colleagues who did several studies to explore or better to confirm the kinetics of BPA in humans and in several laboratory animals (Doerge et al. 2010a, b, c, 2011a, b, 2012; Fisher et al. 2011; Teeguarden and Barton 2004; Teeguarden et al. 2005, 2011, 2013, 2015a, b, 2016; Thayer et al. 2015; Yang et al. 2013, 2015).

Teeguarden, Doerge, and some colleagues completely confirmed previously published data (Völkel et al. 2002, 2005) in humans, which were criticized by Vandenberg et al. In two reviews published in 2010 in Environmental Health Perspectives they wrote, "The two toxicokinetic studies that suggested human BPA exposure is negligible have significant deficiencies, are directly contradicted by hypothesis-driven studies, and are therefore not reliable for risk assessment purposes" (Vandenberg et al. 2010a, b). But the authors defrauded a third kinetic study from Tsukioka et al. (2004) who obtained comparable results as published by Völkel et al. $(2002,2005)$, which were criticized by Vandenberg et al. (2010a, b).

In addition, a kinetic study co-authored by NIEHS members known to be crucial in respect to BPA (Thayer et al. 2015) confirmed also the data of Völkel et al. (2002, 2005).

An answer to the not substantiated criticism was previously published by members of the Advisory Committee of the German Society of Toxicology (Hengstler et al. 2011). In this review all criticism of Vandenberg et al. was refuted point by point. For example Vandenberg criticized the "limit of detection (LOD) were not sufficient, the authors reported two different time points for maximal plasma concentrations of BPA or the potential of adverse effects of BPA at low levels was not considered". But in the year 2000 the low dose discussion in case of BPA was just starting and Völkel et al. (2002) used $5 \mathrm{mg}(83 \mu \mathrm{g} / \mathrm{kg}$ b.w.) and Völkel et al. (2005) used $25 \mu \mathrm{g}(0.42 \mu \mathrm{g} / \mathrm{kg}$ b.w.) (estimated maximum human daily intake of adults, http://ec.europa. eu/food/fs/sc/scf/out128_en.pdf), which are clearly lower doses compared to Hass et al. (2016) and Mandrup et al. (2016) who applied doses as high as $50 \mathrm{mg} / \mathrm{kg}$ b.w. and used also the term "low dose". The two different time points occurred because two different studies were performed as clearly stated in the text and the LOD was sufficient to determine all the kinetic data. All the criticism with 
"The two toxicokinetic studies performed to date (Völkel et al. 2002, 2005), which suggest that human exposure is negligible, have significant flaws and are therefore not reliable for risk assessment purposes" was refuted and implies that Vandenberg et al. didn't read the publications carefully or they don't understand kinetics and exposure science.

They also criticized that "additionally, the BPA-glucuronide levels reported in blood are higher than the total BPA concentrations". Especially if two different analytical methods were used as in the study of Völkel et al. the obtained concentrations are very similar with overlapping error bars. Moreover, two analytical methods (BPA with GC-MS, BPA-Glucuronide with LC-MS/MS) were used. The same methods (Vandenberg et al. 2010b) called " $C D C$ analytical procedure ... is the gold standard" although the CDC published the analytical methods (GC-MS in 2003 and LC-MS/MS in 2005) (Kuklenyik et al. 2003; Ye et al. 2005) clearly after Völkel et al. (2002) and, therefore, the "gold standard" was already published before the CDC did. Again Vandenberg et al. give the impression that they have only little knowledge in the field of analytical chemistry, which is the basis for kinetics and exposure science.

In the next months, all the studies performed in the Consortium Linking Academic and Regulatory Insights on BPA Toxicity (CLARITY-BPA) program http://www. niehs.nih.gov/research/programs/endocrine/bpa_initiatives/index.cfm will be published, and I am excited to see whether the FDA have to revise their assessment on BPA or not. Since people like Vandenberg, Prins, Gies, and others prompted additional research on BPA (Gies et al. 2009), which shows the term "wish list", clearly you may have some doubt that regulatory toxicologists will get really different and up to now unknown data related to the hazard of BPA. All "significant flaws" in the field of analytical chemistry and kinetics apparently detected by Vandenberg et al. were completely refuted as discussed in this letter. In addition these researchers draw often conclusions are contrary to their own statements or in other words "biomonitoring studies should be used by regulatory agencies to assess human exposure levels" (Vandenberg et al. 2010b) which was done by the European Food Safety Authority (EFSA) http://onlinelibrary.wiley.com/doi/10.2903/j. efsa.2015.3978/abstract; jsessionid $=4430$ B03DBCCC556 5A689D7A4519CFCE8.f01t02 with "The highest aggregated exposure of $1.449 \mu \mathrm{g} / \mathrm{kg}$ b.w. per day was estimated for adolescents. Biomonitoring data were in line with estimated internal exposure to total BPA from all sources." Therefore, I fully agree that "biomonitoring studies should be used," but also researchers and ethical committees for animal welfare should use biomonitoring studies to find the correct dose in studies, which should be useful for regulatory toxicologists. A range from $25 \mu \mathrm{g} / \mathrm{kg}$ b.w. to $50 \mathrm{mg} / \mathrm{kg}$ b.w. is clearly not correct!

\section{References}

Doerge DR, Twaddle NC, Vanlandingham M, Fisher JW (2010a) Pharmacokinetics of bisphenol A in neonatal and adult SpragueDawley rats. Toxicol Appl Pharmacol 247:158-165

Doerge DR, Twaddle NC, Woodling KA, Fisher JW (2010b) Pharmacokinetics of bisphenol A in neonatal and adult rhesus monkeys. Toxicol Appl Pharmacol 248:1-11

Doerge DR, Vanlandingham M, Twaddle NC, Delclos KB (2010c) Lactational transfer of bisphenol A in Sprague-Dawley rats. Toxicol Lett 199:372-376

Doerge DR, Twaddle NC, Vanlandingham M, Brown RP, Fisher JW (2011a) Distribution of bisphenol A into tissues of adult, neonatal, and fetal Sprague-Dawley rats. Toxicol Appl Pharmacol 255:261-270

Doerge DR, Twaddle NC, Vanlandingham M, Fisher JW (2011b) Pharmacokinetics of bisphenol $\mathrm{A}$ in neonatal and adult CD-1 mice: inter-species comparisons with Sprague-Dawley rats and rhesus monkeys. Toxicol Lett 207:298-305

Doerge DR, Twaddle NC, Vanlandingham M, Fisher JW (2012) Pharmacokinetics of bisphenol $\mathrm{A}$ in serum and adipose tissue following intravenous administration to adult female CD-1 mice. Toxicol Lett 211:114-119

Fisher JW, Twaddle NC, Vanlandingham M, Doerge DR (2011) Pharmacokinetic modeling: prediction and evaluation of route dependent dosimetry of bisphenol A in monkeys with extrapolation to humans. Toxicol Appl Pharmacol 257:122-136

Gies A, Heinzow B, Dieter HH, Heindel J (2009) Bisphenol a workshop of the german federal environment agency-march 30-31, 2009 work group report: public health issues of bisphenol a. Int J Hyg Environ Health 212:693-696

Hass U, Christiansen S, Boberg J, Rasmussen MG, Mandrup K, Axelstad M (2016) Low-dose effect of developmental bisphenol A exposure on sperm count and behaviour in rats. Andrology. doi:10.1111/andr.12176

Hengstler JG, Foth H, Gebel T, Kramer PJ, Lilienblum W, Schweinfurth H, Völkel W, Wollin KM, Gundert-Remy U (2011) Critical evaluation of key evidence on the human health hazards of exposure to bisphenol A. Crit Rev Toxicol 41:263-291

Kasper-Sonnenberg M, Wittsiepe J, Koch HM, Fromme H, Wilhelm M (2012) Determination of bisphenol a in urine from motherchild pairs-results from the duisburg birth cohort study Germany. J Toxicol Environ Health A 75:429-437

Koch HM, Kolossa-Gehring M, Schroter-Kermani C, Angerer J, Bruning T (2012) Bisphenol A in $24 \mathrm{~h}$ urine and plasma samples of the German Environmental Specimen Bank from 1995 to 2009: a retrospective exposure evaluation. J Expo Sci Environ Epidemiol 22:610-616

Kuklenyik Z, Ekong J, Cutchins CD, Needham LL, Calafat AM (2003) Simultaneous measurement of urinary bisphenol A and alkylphenols by automated solid-phase extractive derivatization gas chromatography/mass spectrometry. Anal Chem 75:6820-6825

Kurebayashi H, Harada R, Stewart RK, Numata H, Ohno Y (2002) Disposition of a low dose of bisphenol a in male and female cynomolgus monkeys. Toxicol Sci 68:32-42

Mandrup K, Boberg J, Isling LK, Christiansen S, Hass U (2016) Lowdose effects of bisphenol A on mammary gland development in rats. Andrology. doi:10.1111/andr.12193

Teeguarden JG, Barton HA (2004) Computational modeling of serum-binding proteins and clearance in extrapolations across life stages and species for endocrine active compounds. Risk Anal 24:751-770

Teeguarden JG, Hanson-Drury S (2013) A systematic review of Bisphenol A "low dose" studies in the context of human exposure: a case for establishing standards for reporting "low-dose" effects of chemicals. Food Chem Toxicol 62:935-948 
Teeguarden JG, Waechter JM Jr, Clewell HJ 3rd, Covington TR, Barton HA (2005) Evaluation of oral and intravenous route pharmacokinetics, plasma protein binding, and uterine tissue dose metrics of bisphenol A: a physiologically based pharmacokinetic approach. Toxicol Sci 85:823-838

Teeguarden JG, Calafat AM, Ye X, Doerge DR, Churchwell MI, Gunawan R, Graham MK (2011) Twenty-four hour human urine and serum profiles of bisphenol a during high-dietary exposure. Toxicol Sci 123:48-57

Teeguarden JG, Fisher JW, Doerge DR (2013) Exposure conditions and pharmacokinetic principles: interpreting bisphenol a absorption in the canine oral cavity. Environ Health Perspect 121:A323

Teeguarden JG, Twaddle NC, Churchwell MI, Yang X, Fisher JW, Seryak LM, Doerge DR (2015a) 24-hour human urine and serum profiles of bisphenol A following ingestion in soup: individual pharmacokinetic data and emographics. Data Brief 4:83-86

Teeguarden JG, Twaddle NC, Churchwell MI, Yang X, Fisher JW, Seryak LM, Doerge DR (2015b) 24-hour human urine and serum profiles of bisphenol A: evidence against sublingual absorption following ingestion in soup. Toxicol Appl Pharmacol 288:131-142

Teeguarden JG, Twaddle NC, Churchwell MI, Doerge DR (2016) Urine and serum biomonitoring of exposure to environmental estrogens I: bisphenol A in pregnant women. Food Chem Toxicol 92:129-142

Thayer KA, Doerge DR, Hunt D, Schurman SH, Twaddle NC, Churchwell MI, Garantziotis S, Kissling GE, Easterling MR, Bucher JR, Birnbaum LS (2015) Pharmacokinetics of bisphenol $\mathrm{A}$ in humans following a single oral administration. Environ Int $83: 107-115$

Tsukioka T, Terasawa J, Sato S, Hatayama Y, Makino T, Nakazawa H (2004) Development of analytical method for determining trace amounts of BPA in urine samples and estimation of exposure to BPA. J Environ Chem 14:57-63

Vandenberg LN (2014) Non-monotonic dose responses in studies of endocrine disrupting chemicals: bisphenol a as a case study. Dose Response 12:259-276
Vandenberg LN, Prins GS (2016) Clarity in the face of confusion: new studies tip the scales on bisphenol A (BPA). Andrology. doi:10.1111/andr.12219

Vandenberg LN, Chahoud I, Heindel JJ, Padmanabhan V, Paumgartten FJ, Schoenfelder G (2010a) Urinary, circulating, and tissue biomonitoring studies indicate widespread exposure to bisphenol A. Environ Health Perspect 118:1055-1070

Vandenberg LN, Chahoud I, Padmanabhan V, Paumgartten FJ, Schoenfelder G (2010b) Biomonitoring studies should be used by regulatory agencies to assess human exposure levels and safety of bisphenol A. Environ Health Perspect 118:1051-1054

Völkel W, Colnot T, Csanady GA, Filser JG, Dekant W (2002) Metabolism and kinetics of bisphenol a in humans at low doses following oral administration. Chem Res Toxicol 15:1281-1287

Völkel W, Bittner N, Dekant W (2005) Quantitation of bisphenol A and bisphenol A glucuronide in biological samples by high performance liquid chromatography-tandem mass spectrometry. Drug Metab Dispos 33:1748-1757

Völkel W, Kiranoglu M, Fromme H (2008) Determination of free and total bisphenol A in human urine to assess daily uptake as a basis for a valid risk assessment. Toxicol Lett 179:155-162

Völkel W, Kiranoglu M, Fromme H (2011) Determination of free and total bisphenol A in urine of infants. Environ Res 111:143-148

Yang X, Doerge DR, Fisher JW (2013) Prediction and evaluation of route dependent dosimetry of BPA in rats at different life stages using a physiologically based pharmacokinetic model. Toxicol Appl Pharmacol 270:45-59

Yang X, Doerge DR, Teeguarden JG, Fisher JW (2015) Development of a physiologically based pharmacokinetic model for assessment of human exposure to bisphenol A. Toxicol Appl Pharmacol 289:442-456

Ye X, Kuklenyik Z, Needham LL, Calafat AM (2005) Quantification of urinary conjugates of bisphenol A, 2,5-dichlorophenol, and 2-hydroxy-4-methoxybenzophenone in humans by online solid phase extraction high performance liquid chromatography-tandem mass spectrometry. Anal Bioanal Chem 383:638-644 